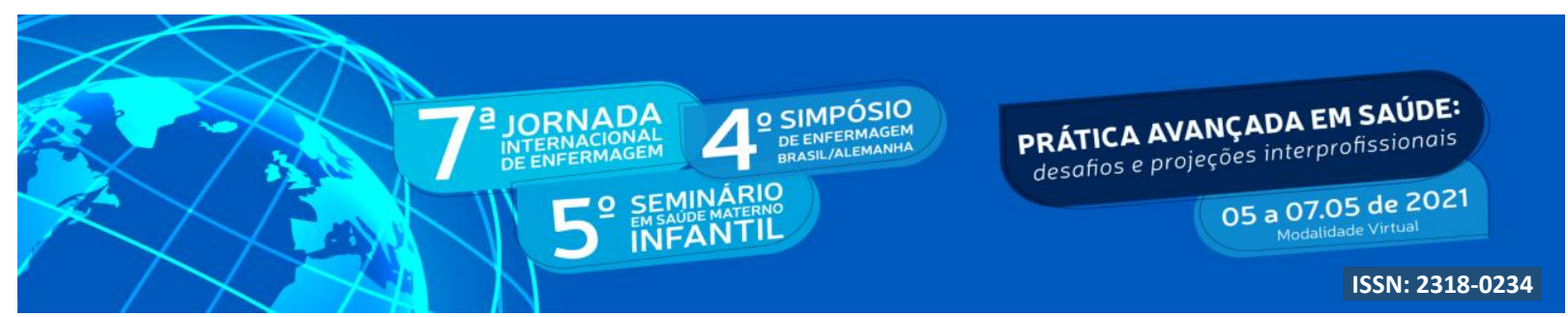

DOI: http://doi.org/10.48195/jie2021-081

\title{
CONTENÇÃO DA COVID-19 E MEDIDAS NÃO FARMACOLÓGICAS ADOTADAS PELOS ESTADOS BRASILEIROS NO INÍCIO DA PANDEMIA ${ }^{1}$
}

\author{
Marli Terezinha Stein Backes² ; Samanta Felippe Will ${ }^{3}$; Maria Vitória de Azeredo \\ Knoblauch $^{4}$; Elisângela Leusin ${ }^{5}$; Dirce Stein Backes ${ }^{6}$; Paula Andréia Echer Dorosz ${ }^{7}$
}

\begin{abstract}
RESUMO
Objetivo: Realizar um levantamento sobre o plano inicial de contenção da Covid-19 e medidas não farmacológicas adotadas pelos estados brasileiros no início da pandemia. Método: Estudo documental. Foi realizada busca de informações em sites de órgãos oficiais dos estados, Secretarias Estaduais de Saúde e Procuradorias Gerais dos Estados. Uilizou-se os primeiros decretos emitidos no início da pandemia/Covid-19 no Brasil, que foram considerados as "primeiras decisões" a nível de cada estado. Os dados foram analisados por meio da análise de conteúdo. Resultados: A partir do surgimento dos primeiros casos de Covid-19 no país, os 27 estados brasileiros instituíram no período de fevereiro a junho de 2020, por meio de diversos decretos, medidas não farmacológicas e restritivas imediatas relacionadas às atividades comerciais, educacionais, desportivas, culturais, religiosas e científicas, mantendo, de modo geral, apenas serviços essenciais. Conclusão: As medidas adotadas contribuíram para a instalação da capacidade de atendimento em saúde a nível hospitalar.
\end{abstract}

Palavras-chave: Contenção de riscos biológicos; Controle de doenças transmissíveis; Evolução fatal; Infecções por coronavirus; Transmissão de doença infecciosa.

\footnotetext{
${ }^{1}$ Trabalho vinculado ao Projeto de Pesquisa Estratégias e intervenções não farmacológicas para a contenção do novo coronavírus/Covid-19: medidas de prevenção, controle e cuidados.

${ }^{2}$ Enfermeira Obstetra. Doutora em Enfermagem. Professora do Departamento de Enfermagem, do Programa de Pós-Graduação em Enfermagem (PEN) da Universidade Federal de Santa Catarina (UFSC) e do Programa de Pós-Graduação Gestão do Cuidado em Enfermagem da UFSC. Líder do GRUPESMUR. Florianópolis, SC, Brasil. E-mail: marli.backes@ufsc.br.

${ }^{3}$ Acadêmica de Enfermagem da $9^{\mathrm{a}}$ Fase do Curso de Graduação em Enfermagem da UFSC. Florianópolis, SC, Brasil. E-mail: samantafelippewill@gmail.com.

${ }^{4}$ Acadêmica de Enfermagem da $3^{a}$ Fase do Curso de Graduação em Enfermagem da UFSC. Florianópolis, SC, Brasil. E-mail: knoblauchmaria27@gmail.com.

${ }^{5}$ Enfermeira Obstetra. Atua na Unidade Neonatal do Hospital Universitário Polydoro Ernani de São Tiago da UFSC. Possui Especialização em Enfermagem Obstétrica e Ginecológica. E-mail: elisangelaleusin@hotmail.com.

${ }^{6}$ Doutora em Enfermagem. Docente do Curso de Enfermagem, do Mestrado Profissional em Saúde Materno Infantil e do Mestrado em Ciências da Saúde e da Vida da Universidade Franciscana (UFN), Santa Maria/RS/Brasil. Coordenadora do Curso de Mestrado Profissional em Saúde Materno Infantil da UFN. Líder do GEPESES. E-mail: backesdirce@ufn.edu.br.

${ }^{7}$ Enfermeira Obstetra. Atua na Atenção Primária à Saúde no município de Biguaçu/SC e na Maternidade Carmela Dutra de Florianópolis/SC. Possui Especialização em Saúde da Família, Urgência e Emergência, Auditoria em Saúde, Gestão em Saúde e em Enfermagem Obstétrica e Ginecológica. E-mail: paulaaedorosz@gmail.com.
} 


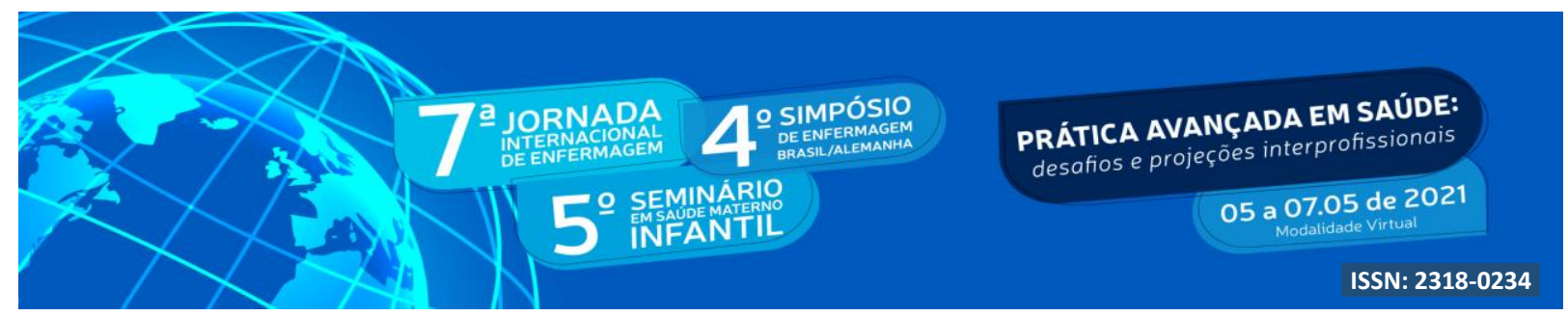

\begin{abstract}
Objective: To conduct a survey on the initial containment plan for Covid-19 and non-pharmacological measures adopted by Brazilian states at the beginning of the pandemic. Method: Documentary study. Information search was carried out on the websites of official state agencies, State Health Departments and State Attorney General's Offices. The first decrees issued at the beginning of the pandemic/Covid19 in Brazil were used, which were considered the "first decisions" at the level of each state. The data were analyzed through content analysis. Results: From the emergence of the first cases of Covid-19 in the country, the 27 Brazilian states instituted in the period from February to June 2020, through various decrees, immediate non-pharmacological and restrictive measures related to commercial, educational, sports activities, cultural, religious and scientific, maintaining, in general, only essential services. Conclusion: The measures adopted contributed to the installation of health care capacity at the hospital level.
\end{abstract}

Key Words: Communicable diseases control; Containment of biohazards; Coronavirus infections; Fatal outcome; Disease Transmission, Infectious.

\title{
1. INTRODUÇÃO
}

O vírus SARS-CoV-2, mais conhecido como novo coronavírus, teve seus primeiros casos de pneumonia relatados em 31 de dezembro de 2019, na cidade de Wuhan, província de Hubei, na China. Foi identificado no início de janeiro, porém sua origem era ainda desconhecida. Os primeiros casos foram associados a um mercado de frutos marinhos e estudos tem apontado para a origem relacionada a algumas espécies de morcegos, que ao terem o contato com humanos teriam transmitido o vírus a eles (UNIVERSIDADE NOVA DE LISBOA, 2020). O que se sabe é que o vírus se hospedou em humanos e, após os primeiros casos, foi verificado que ele também se espalhava entre estes de uma forma rápida, tanto que até o dia $1^{\circ}$ de março, Wuhan contava com $81 \%$ dos casos da china, que apresentava 79.986 casos (KRAEMER et al., 2020).

No dia 23 de janeiro de 2019, a china impôs sobre Wuhan uma série de medidas de controle para evitar que o vírus saísse de seu local de origem, que um dia depois foram empregadas em todas as províncias de Hubei. Dentre elas, o cordão sanitário, proibindo viagens e movimentação de pessoas, além de proibirem reuniões públicas e imporem fechamento de locais de entretenimento e escolas (TIAN et al., 2020). Outras medidas muito importantes também foram a testagem, manejo clínico e isolamento de casos confirmados e dos suspeitos, além da investigação e isolamento de pessoas que tiveram contato com doentes infectados e a disseminação de informações para a população. 


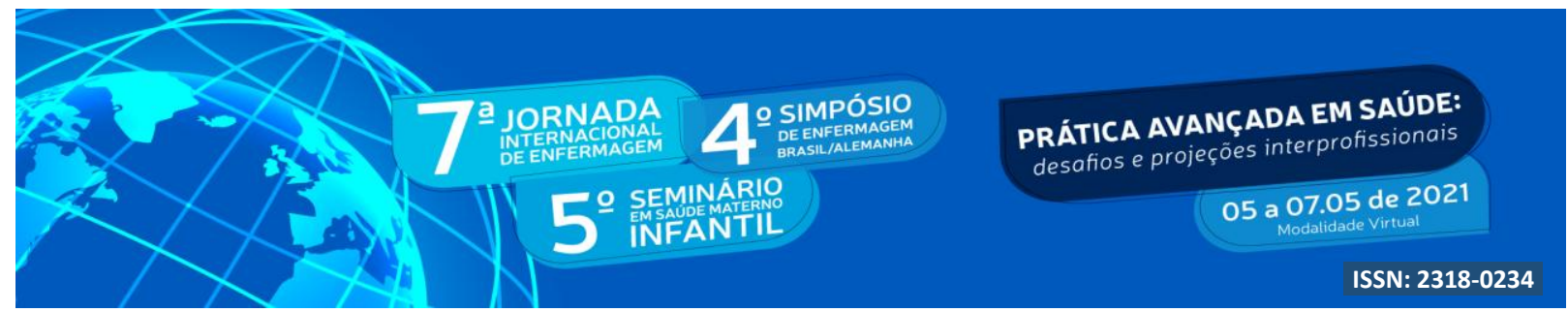

Estudo tem mostrado que as medidas adotadas na China postergaram a chegada do vírus em outras cidades por três dias e diminuíram em $96 \%$ o total de casos calculados para o $50^{\circ}$ dia da transmissão do vírus (TIAN et al., 2020). Ao analisarem a transmissibilidade do vírus (quantas pessoas ele pode infectar a partir de uma), a razão R0 era de 3,15, sendo que para o vírus continuar existindo a razão deveria ser R0 1 (quando uma pessoa infectada transmite o vírus para mais uma). Quando as medidas de controle adotadas estavam findando na China, no final da primeira onda de Covid-19 (em março de 2020), a transmissibilidade passou para R0 0,04 e o país conseguiu controlar a transmissão (KRAEMER et al., 2020).

No Brasil, o primeiro caso confirmado de Covid-19 ocorreu em São Paulo, no dia 26 de fevereiro de 2020 a partir de um paciente de 61 anos que deu entrada no Hospital Israelita Albert Einstein, após viagem para Itália. Rapidamente os casos foram aumentando e no dia 01 de abril de 2020 todas as cinco regiões do país já apresentavam casos e mortes: região Sudeste (4.223 casos e 195 mortes), região Nordeste (1.007 casos e 27 mortes), região Sul (765 casos e 9 mortes) região Centro-Oeste (504 casos e 5 mortes), região Norte (337casos e 4 mortes) (CARVALHO, 2020).

O impacto do caos que essa pandemia tem causado pode ser demonstrado representativamente pelo número de pessoas infectadas e pelo número de mortes já registrados. Considerando os registros oficiais até 17/01/2021, ocorreram no mundo 93.217.287 casos acumulados e 2.014.957 mortes acumuladas. O país com o maior número de casos absolutos é os Estados Unidos da América (23.344.423 casos e 7.052.6 casos por 100 mil habitantes, 389.084 mortes e 117.5 mortes por 100 mil habitantes), em segundo lugar, encontra-se a India em número de casos acumulados (10.557.985 casos, 765.1 casos por 100 mil habitantes, 152.274 mortes e 11.0 mortes por 100 mil habitantes). O Brasil está em segundo lugar em número de mortes acumuladas (8.393.492 casos, 3.948 .8 casos por 100 mil habitantes, 208.246 mortes e 98.0 mortes por 100 mil habitantes) (WORLD HEALTH ORGANIZATION, 2021).

Entretanto, considerando que o Brasil é um país de dimensões continentais, ao se considerar, na data de 17/01/2021, o número de mortes por 100 mil habitantes, 22 países superaram o número de mortes em relação ao Brasil (México (107.8), Argentina (100.1), Peru (117.2), Panamá (108.7), Reino Unido (130.5), França (106.9), Itália (135.3), Espanha (113.5), Czechia (133.9), Suécia (Czechia), Bélgica (176.3), Hungria (117.4), Eslovênia 


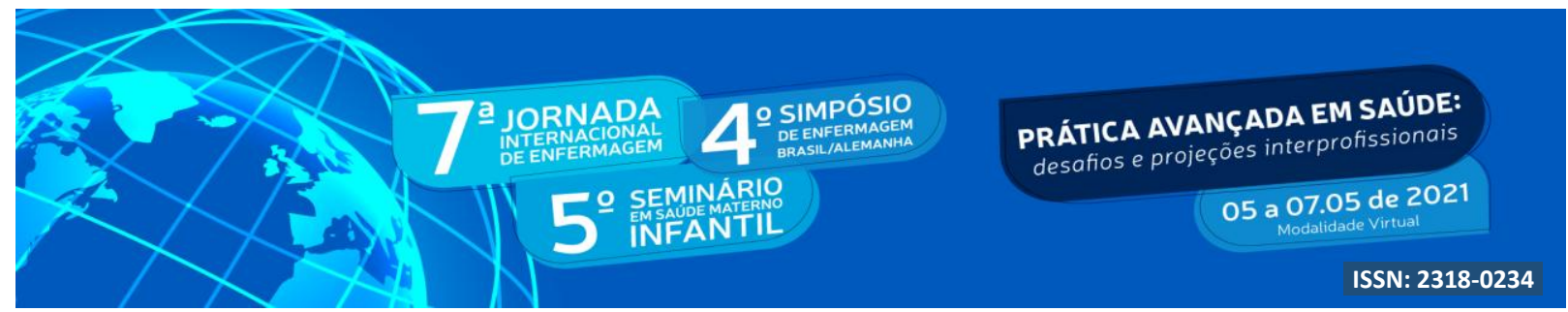

(160.0), Croácia (112.4), Bulgária (122.0), Montenegro (118.6), Macedônia do Norte (129.4), Armênia (101.0), Bósnia e Herzegovina (135.6), Andorra (117.8), San Marino (191.5) e Liechtenstein (104.9) (WORLD HEALTH ORGANIZATION, 2021). Dessa maneira, não dá para dizer que o Brasil é o segundo país em número de mortes por Covid-19.

Um dos principais objetivos da adoção das medidas de controle não farmacológicos que incluem o distanciamento físico (manter cerca de 2 metros de distância entre uma pessoa e outra) e o isolamento social (evitar aglomerações) para o novo coronavírus é fazer com que os sistemas de saúde possam dar conta da demanda de atendimento de pacientes com Covid19, evitando que as pessoas morram por não terem acesso a um serviço de saúde ou que o cuidado empregado não tenha qualidade.

Por sua vez, Tratamentos farmacológicos para a Covid-19 demandariam uma capacidade dobrada do sistema de saúde, visto que diminuiriam o tempo de permanência e a gravidade da doença nos pacientes (KISSLER et al., 2020). De acordo com os mesmos autores, enquanto não se tem tratamentos farmacológicos e não se sabe quanto dura a imunidade de uma pessoa que teve Covid-19, o distanciamento físico/social é uma estratégia que pode evitar o sobrecarregamento de sistemas de saúde e dar tempo para que descobertas importantes sejam feitas. Segundo eles, o distanciamento físico/social também se mostra mais importante quando os primeiros casos são descobertos, assim, evita-se que haja uma explosão de casos e o sistema de saúde não dê conta de atendê-los.

Ainda não se sabe se o distanciamento físico/social é a estratégia mais eficaz para a diminuição da transmissão do vírus. Entretanto, as aglomerações e a ação da mobilidade humana sobre a transmissão do vírus já foram confirmadas, o que dá pistas aos gestores sobre como se pode lidar com essa pandemia (TIAN et al., 2020). E, as estratégias de distanciamento físico/social também devem estar associadas a um bom nível de testagem e isolamento dos casos conhecidos (WALKER et al., 2020). Entretanto, o distanciamento físico/social também vem afetando a economia e é eticamente questionável, pois afeta de forma profunda as relações e as decisões de cada indivíduo (LEWNARD; LO, 2020) e tem impactado diretamente na vida das pessoas, famílias e sociedade em geral.

O Brasil é um país vasto e plural, onde a cultura, demografia, condições climáticas e outras questões variam de um estado para outro. E as cinco macrorregiões têm diferenças históricas na capacidade e cobertura do sistema de saúde (RANZANI et al., 2021). Diante da 


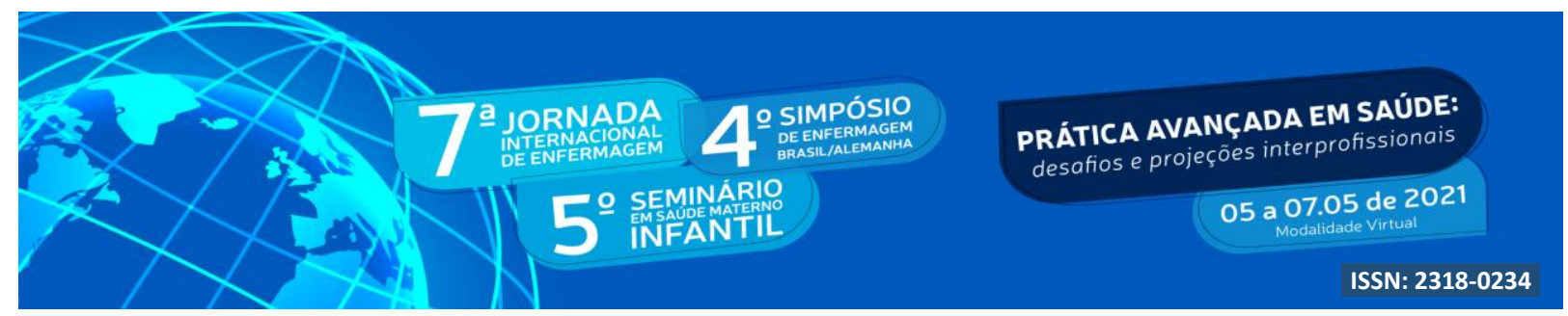

vigência da pandemia da Covid-19, surgiram muitas dúvidas e incertezas e medidas imediatas tiveram que ser adotadas. Houve a mobilização interna em cada país e cada estado brasileiro teve autonomia para estabelecer o seu plano de contingência para conter a Covid-19. Nessa direção, este estudo apresenta como pergunta de pesquisa: Qual o plano inicial de contenção da Covid-19 e as primeiras medidas não farmacológicas adotadas pelos estados brasileiros no início da pandemia?

\section{OBJETIVO}

Realizar um levantamento sobre o plano inicial de contenção da Covid-19 e as prmeiras medidas não farmacológicas adotadas pelos estados brasileiros no início da pandemia.

\section{METODOLOGIA}

Estudo documental. Foi realizada a busca de informações em sites de órgãos oficiais dos estados, das Secretarias Estaduais de Saúde e Procuradorias Gerais dos Estados. Utilizouse os primeiros decretos emitidos no início da pandemia da Covid-19 no Brasil, os quais foram considerados as "primeiras decisões" a nível de cada estado. Todos os decretos consultados foram lançados entre fevereiro e junho de 2020.

Os dados coletados foram analisados conforme a análise de conteúdo (BARDIN, 2011). Que foi norteada por três pólos cronológicos: a pré-análise; a exploração do material; e o tratamento dos resultados, a inferência e a interpretação. A pré-análise iniciou com a leitura flutuante que consiste em estabelecer contato com os documentos analisados, ou seja, com os decretos e demais documentos oficiais, para conhecer o seu conteúdo e deixar-se invadir por impressões e orientações. Estes decretos e demais documentos foram organizados em um quadro. Na exploração do material ocorreram as operações de codificação, decomposição e enumeração dos dados.

\section{RESULTADOS E DISCUSSÃO}

Após o surgimento dos primeiros casos de Covid-19 no país, os 27 estados brasileiros declararam Situação de Emergência em Saúde Pública e/ou Estado de Calamidade Pública conforme a situação do momento e instituíram, entre 28 de fevereiro a 05 de junho de 2020 


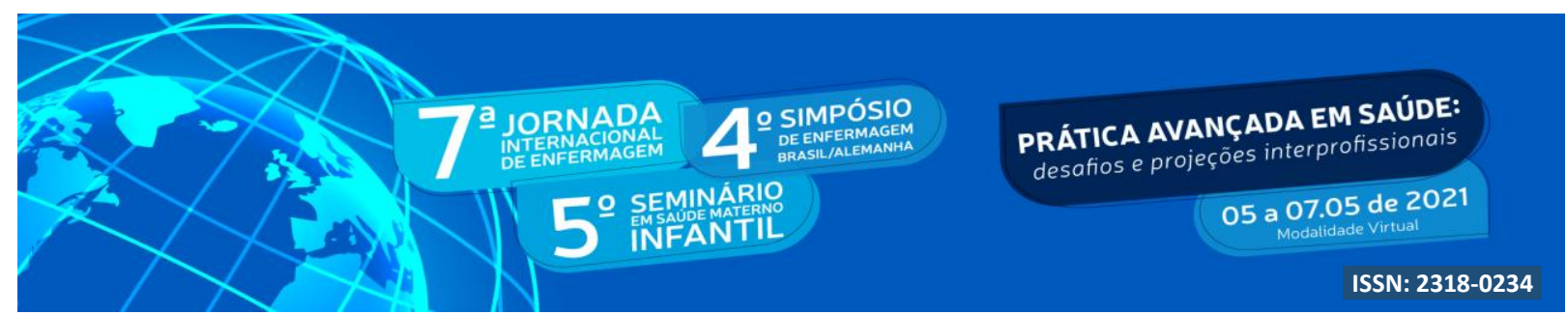

por meio de diversos decretos, com prorrogações, medidas restritivas imediatas relacionadas às atividades comerciais, educacionais, desportivas, culturais, religiosas e científicas, e mantiveram, de um modo geral, apenas os serviços considerados essenciais, como instituições e serviços de saúde, farmácias, supermercados, postos de combustíveis, segurança e saneamento básico. A partir dos dados levantados e coletados de forma online, buscou-se realizar uma síntese das informações obtidas referentes a cada estado brasileiro.

Foram suspensos os serviços e atividades considerados não essenciais ou foi limitado o seu funcionamento em estabelecimentos e centros comerciais, em feiras, exposições, lojas, shoppings centers, cinemas, centros culturais, teatros, museus, zoológicos, parques ecológicos, bibliotecas, bares, restaurantes, lanchonetes, boates, em casas de show, casas noturnas, eventos comemorativos, salões de beleza e similares, em centros de artesanato, em agências bancárias e casas lotéricas, em cultos e eventos religiosos de qualquer credo, em templos e igrejas, excursões, eventos científicos e demais eventos e/ou agrupamentos/aglomeração a partir de cinco pessoas (ou 10, 50, 100 ou mais, a depender do local e se o evento era aberto ou fechado), em local público e privado, que promovem atividade física, lazer e similares. Também foi suspensa a entrada de novos hóspedes no ramo hoteleiro e visita a pontos turísticos, visitas às unidades do sistema penitenciário e socioeducativas, assim como visitas a pacientes internados nas unidades hospitalares. Atividades educacionais e cursos técnicos foram suspensos em escolas e universidades na rede pública e privada, férias escolares foram antecipadas e, após, ocorreu a suspensão das aulas presenciais.

Quanto às atividades desportivas, foram suspensos eventos desportivos em ginásios e estádios de futebol, quadras poliesportivas, academias, clubes e centros de ginástica, praças esportivas e similares, em parques ou locais abertos ao público que oportunizassem aglomeração. Foi decretada a proibição de aglomeração em praias e parques, frequentar lagos e piscinas, e a interdição de praias.

Houve a proibição da circulação de transporte coletivo de natureza rodoviária, ferroviária e aquaviária, municipal, intermunicipal e interestadual, público ou privado, ou o seu funcionamento apenas com a capacidade de passageiros sentados (exceto em situações de urgência e emergência), enquanto transportes como uber e táxi não deveriam exceder a quantidade de dois passageiros e um motorista. Foram interrompidas as operações do serviço 


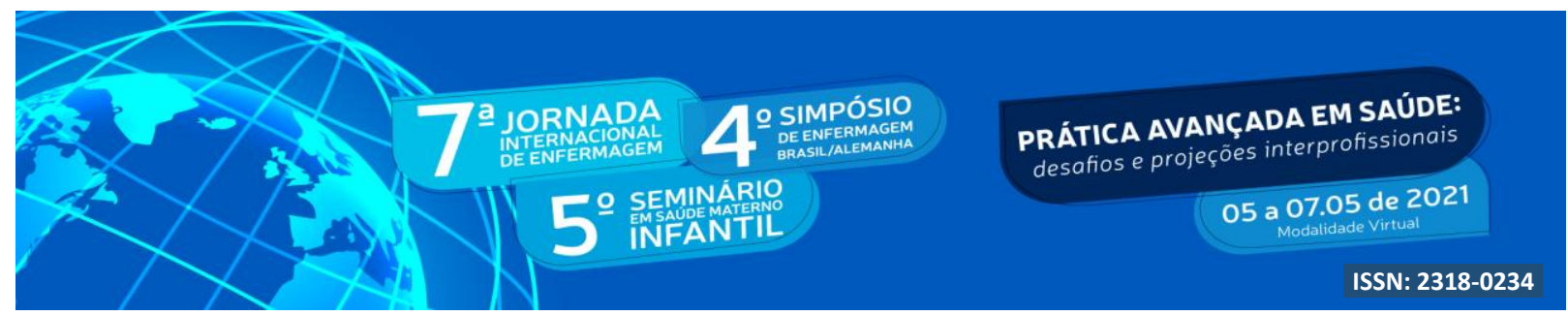

de transporte metroviário (Ceará), proibição da operação aeroviária em aeroportos estaduais (Rondônia), controle da circulação de veículos e pessoas em alguns municípios (Pernambuco), o ingresso no território do Estado de Rondônia de transporte coletivo, seja ele público ou privado, de território internacional (Rondônia). Foi proibida a atracação de embarcações de qualquer país ou estado com casos confirmados de coronavírus e a circulação de ônibus interestaduais de estados com casos confirmados de coronavírus ou que já tenham declarado Estado de Emergência (Sergipe). Em Santa Catarina foi declarado o fechamento de fronteiras com o Rio Grande do Sul e Paraná no dia 20 de março.

Em relação aos serviços de saúde, foram suspensas consultas eletivas, exames e procedimentos ambulatoriais, cirurgias eletivas em hospitais públicos e privados e clínicas odontológicas e de fisioterapia (exceto em casos de urgência e emergência). Na região sul do país foi implementada a antecipação da campanha de vacinação contra Influenza para o dia 23 de março, que foi ampliada para além dos postos de saúde, como escolas e universidades, priorizando grupos mais vulneráveis, como os idosos (Paraná, Rio Grande do Sul e Santa Catarina). No estado do Maranhão foi lançado no dia 25 de março o Protocolo de Isolamento Domiciliar a todos os casos de síndromes gripais, independente da gravidade, com vigência de 14 dias.

Entre as medidas não farmacológicas adotadas, estas compreendiam a recomendação para que a população só saísse de casa para fins de atividades essenciais, como para comprar alimentos e necessidade de cuidados de saúde, respeito ao distanciamento físico/social e medidas sanitárias, a distância mínima de dois metros entre as pessoas e entre mesas de bares e restaurantes, autorização para teletrabalho, uso obrigatório de máscara pela população. Também aumentou o controle do fluxo de pessoas nas divisas dos Estados. Foram instituídas punições e multas para quem não cumprisse as medidas de contenção, uma vez em que esse descumprimento pode ser enquadrado como crime contra a saúde pública e crime de desobediência.

Desde junho de 2020 as medidas adotadas pelos estados brasileiros foram sendo flexibilizadas gradativamente, com a reabertura dos serviços não essenciais, considerando os impactos econômicos na sociedade como um todo. Entretanto, a pandemia da Covid-19 ainda estava com a curva de casos e mortes elevada e aumentando no Brasil, que na época estava enfrentando a primeira onda. 


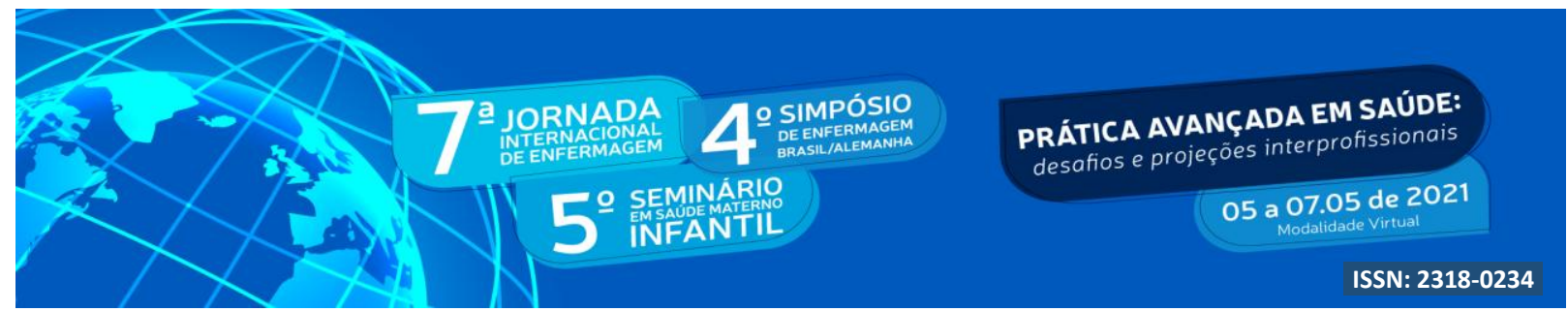

A região Sudeste foi a mais afetada inicialmente, pois é a região que apresenta maior mobilidade internacional. Na sequência, as regiões Norte e Nordeste que representam as regiões menos favorecidas do país, foram amplamente atingidas, com grandes repercussões na capacidade de saúde instalada que mostrou-se insuficiente.

O Brasil foi um dos países que experimentou a pandemia da Covid-19 de crescimento mais rápido e o estado do Amazonas, situado no norte do Brasil, foi o mais afetado (HALLAL et al., 2020). O país enfrentou a primeira onda em todo seu território por um longo período que compreendeu os meses de abril a setembro de 2020.

Estudo retrospectivo realizado no Brasil referente ao período de 16 de fevereiro e 15 de agosto de 2020 realizou uma análise das características dos pacientes internados em hospitais com Covid-19 e examinou o impacto da doença nos recursos de saúde e na mortalidade intra-hospitalar, incluindo as cinco macrorregiões do país nas quais foi constatada ampla distribuição da doença. Nas semanas epidemiológicas 19 a 22 (03 a 30/05/2020), os casos estavam concentrados nas regiões Norte, Nordeste e Sudeste; Já nas semanas 27 a 30 (28/06 até 25/07/2020), os casos se espalharam para o Centro-Oeste e o Sul. Neste período, 254.288 pacientes com Covid-19 foram admitidos nos hospitais. A média de idade era de 60 anos, $47 \%$ tinham idade inferior a 60 anos, $56 \%$ eram do sexo masculino, $16 \%$ não tinham comorbidades. A mortalidade hospitalar foi alta (38\% em geral), mesmo em pacientes com menos de 60 anos, e agravado pelas disparidades regionais existentes no sistema de saúde. Entre os pacientes admitidos na UTI, 59\% morreram (3 de cada 5 admitidos) assim como $80 \%$ dos pacientes ventilados mecanicamente (4 de cada 5). Foi observada importante variabilidade regional: A mortalidade hospitalar entre pacientes com menos de 60 anos foi de $31 \%$ no Nordeste contra $15 \%$ no Sul. Em relação ao percentual de mortalidade em pacientes sob ventilação mecânica invasiva, esta foi maior na região norte e menor na região sul e, no Nordeste, $16 \%$ dos pacientes receberam ventilação mecânica invasiva fora da UTI em comparação com $8 \%$ na região sul (RANZANI et al., 2021).

Países com rendas diferentes têm características diferentes que precisam ser avaliadas para entender a dispersão viral e para a tomada de decisão e, aqueles com menores rendas tendem a ter menor capacidade nos sistemas de saúde (WALKER et al., 2020). Segundo os autores, nesses países, uma das características preocupantes é a configuração das habitações 


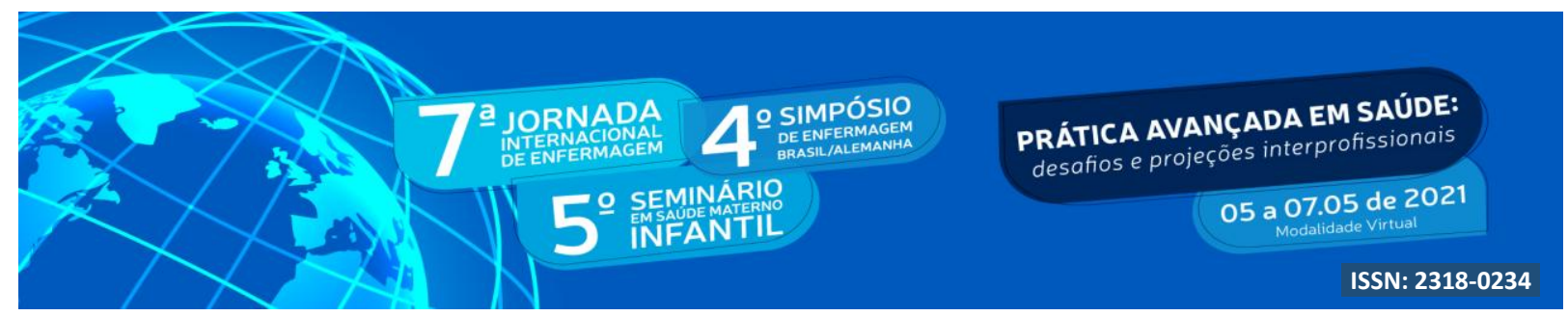

das famílias, que tendem a ter mais membros e viverem mais próximas, de maneira que uma pessoa com Covid-19 pode transmitir o vírus para as várias outras que vivem no mesmo local.

Um exemplo típico dessa realidade são as favelas, que fazem parte do contexto dos países mais pobres e em desenvolvimento como o Brasil, onde, além dos parentes conviverem todos em um espaço pequeno, geralmente no mesmo terreno, existem também várias famílias morando muito próximas, o que torna até o distanciamento físico/social algo difícil de ser alcançado.

\section{CONCLUSÃO}

A partir do levantamento realizado neste estudo constatou-se que o plano inicial de contenção da Covid-19 e as primeiras medidas não farmacológicas adotadas pelos 27 estados brasileiros no início da pandemia quando surgiram os primeiros casos de Covid-19 no país foram instituídas no período de fevereiro a junho de 2020 por meio de diversos decretos com medidas restritivas imediatas relacionadas às atividades comerciais, educacionais, desportivas, culturais, religiosas e científicas, e mantiveram de um modo geral, apenas os serviços considerados essenciais, como instituições e serviços de saúde, farmácias, supermercados, postos de combustíveis, saneamento básico, entre outros.

As medidas restritivas adotadas, tais como a quarentena, o isolamento social, o distanciamento físico entre as pessoas e o uso obrigatório de máscara pela população em geral foram de grande importância e contribuíram para a instalação da capacidade de atendimento em saúde a nível hospitalar, com algumas diferenças regionais.

No momento (21/03/2021), o mundo está passando pela segunda onda da Covid-19, de magnitude maior do que a primeira e com a existência e o surgimento de novas variantes, sendo o Brasil novamente o epicêntro da pandemia e com todos os estados sendo afetados. Já existe a vacina contra a Covid-19 sendo aplicada no mundo inteiro, mas de forma mais lenta nos países mais pobres, incluindo o Brasil. Entretanto, as medidas não farmacológicas como o distanciamento físico e o uso de máscara continuam sendo essenciais e a sua não adoção, por si só, representa um risco à saúde humana e saúde pública, pois ainda persistem muitas dúvidas e incertezas, inclusive sobre a eficácia da vacina contra a Covid-19. Independentemente de ser o vírus selvagem (SARS-CoV-2) ou o vírus mutante (nova variante), ao tomar os cuidados necessários é possível diminuir a circulação dele. 


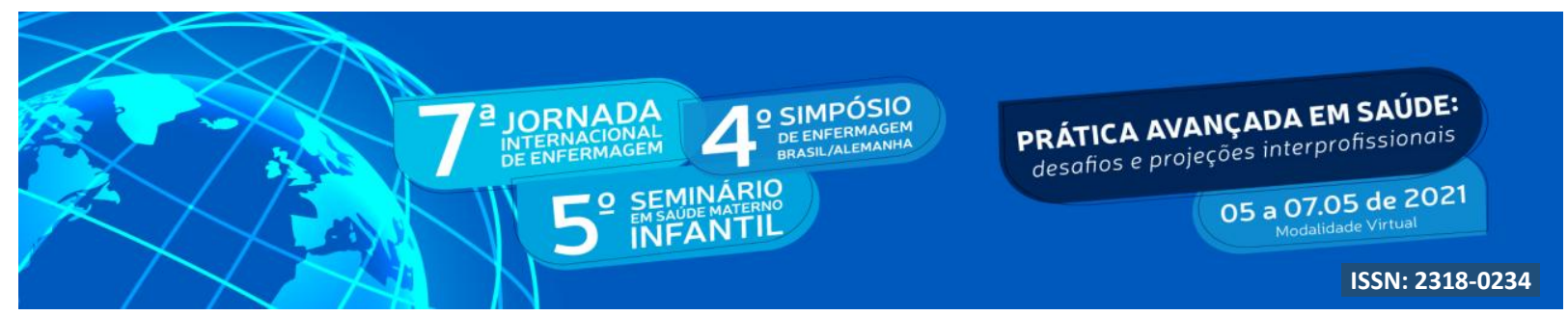

\section{REFERÊNCIAS}

BARDIN, L. Análise de conteúdo. Tradução Luís Antero Reto, Augusto Pinheiro. São Paulo: Edições 70; 2011.

CARVALHO, I. Contenção. Quais são as medidas adotadas por cada estado brasileiro contra o coronavírus. Brasil de Fato, São Paulo, 01 de Abril de 2020, às 22:21. Disponível em: https://www.brasildefato.com.br/2020/04/01/quais-sao-as-medidas-adotadas-por-cada-estadobrasileiro-contra-o-coronavirus. Acesso em: 22 Jan 2021.

HALLAL, P. C., et al. SARS-CoV-2 antibody prevalence in Brazil: results from two successive nationwide serological household surveys. The Lancet Global Health; v.8, p.e1390-e1398, 2020. doi: 10.1016/ S2214-109X(20)30387-9.

KISSLER, S. M., et al. Projecting the transmission dynamics of SARS-CoV-2 through the postpandemic period. Science 2020; v.368, n.6493, p.860-868, 2020. doi:

10.1126/science.abb5793.

KRAEMER, M. U. G., et al. The effect of human mobility and control measures on the COVID-19 epidemic in China. Science; v.368, n.6490, p.493-497, 2020. doi: 10.1126/science.abb4218.

LEWNARD, J. A.; LO, N. C. Scientific and ethical basis for social-distancing interventions against COVID-19. The Lancet Infectious Diseases; v.20, n.6, p.631-633, 2020. doi: 10.1016/S1473-3099(20)30190-0.

RANZANI, O. T., et al. Characterisation of the first 250000 hospital admissions for COVID19 in Brazil: a retrospective analysis of nationwide data. Published online January 15, 2021. doi: 10.1016/S2213-2600(20)30560-9.

TIAN, H., et al. An investigation of transmission control measures during the first 50 days of the COVID-19 epidemic in China. Science; v.368, n.6491, p.638-642, 2020. doi:

10.1126/science.abb6105.

UNIVERSIDADE NOVA DE LISBOA. Instituto de Higiene e Medicina Tropical. Dossier: Origem e dispersão pandémica do coronavírus SARS-CoV-2, causador da COVID-19 (atualizado). 2020. Disponível em: https://www.ihmt.unl.pt/origem-e-dispersao-pandemicado-coronavirus-sars-cov-2-causador-da-covid-19/. Acesso em: 21 jan. 2020.

WALKER, P. G. T., et al. The Global Impact of COVID-19 and Strategies for Mitigation and Suppression. Imperial College London, 2020. doi: 10.25561/77735.

WORLD HEALTH ORGANIZATION. COVID-19 Weekly Epidemiological Update. Data as received by WHO from national authorities, as of 17 January 2021, 10 am CET [Internet]. 2021. Available from: https://www.who.int/publications/m/item/weekly-epidemiologicalupdate---19-january-2021. Acessed by: 22 Jan 2021. 